\title{
Cardiac surgeons: Are we too tight?
}

John Calhoon, MD

\footnotetext{
From the Department of Cardiothoracic Surgery, UTH/UHS Heart and Vascular Institute, University of Texas Health Science Center San Antonio, San Antonio, Tex.

Disclosures: Author has nothing to disclose with regard to commercial support.

Received for publication Aug 30, 2017; accepted for publication Aug 30, 2017; available ahead of print Sept 22, 2017.

Address for reprints: John Calhoon, MD, Department of Cardiothoracic Surgery, UTH/UHS Heart and Vascular Institute, University of Texas Health Science Center San Antonio, Suite 211L, 7703 Floyd Curl Dr, San Antonio, TX 78229 (E-mail: Calhoon@uthscsa.edu or garciaip@uthscsa.edu).

J Thorac Cardiovasc Surg 2018;155:142

$0022-5223 / \$ 36.00$

Copyright $(\underset{c}{ } 2017$ by The American Association for Thoracic Surgery

http://dx.doi.org/10.1016/j.jtcvs.2017.08.110
}

This study by Pierce and colleagues ${ }^{1}$ in this issue of the Journal is a novel one. We have seen limited work in the area of measuring technical suturing performance such as this. It is both interesting and yet not surprising that two different experienced surgeons had significantly different suturing tensions. What is not known is far more than what Pierce and colleagues ${ }^{1}$ identify about implanting rings. What about the effects of spacing, suture depth, number or type of sutures, and the risk of suture dehiscence from being either too loose or too tight? Does suture annular spacing match well with the sutures through the ring? Does taking more or less of the actual ring silicone elastomer and cloth affect measured tension? Does tension differ significantly in undersized rings versus those sized to the annulus? All these questions affect the long-term outcome of every aspect of suturing technique.

Having highlighted these concerns, this study of Pierce and colleagues ${ }^{1}$ only focuses on a single aspect of our work. We must realize that these tensions are measured in a static environment. Valves are implanted in a beating heart, with an annulus constantly in some degree of motion, and whether the ring is rigid or soft, it is constantly exposed to tension after the suture is tied. In addition, some surgeons place sutures with almost no lateral force on the tissue as they roll the suture through the desired site with ease and others may force the needle to some degree as they try to adapt the tissue to the position of the needle. Some surgeons place sutures deeper in tissue, and others feel it best to place the same sutures much more shallowly. It has been impressive to me to see the differences in suture placement by the many residents as they work and learn from us as faculty. Nowhere has these differences been highlighted as much as they are in neonatal interrupted aortic arch or hypoplastic bleeding. the line.

\section{Reference}

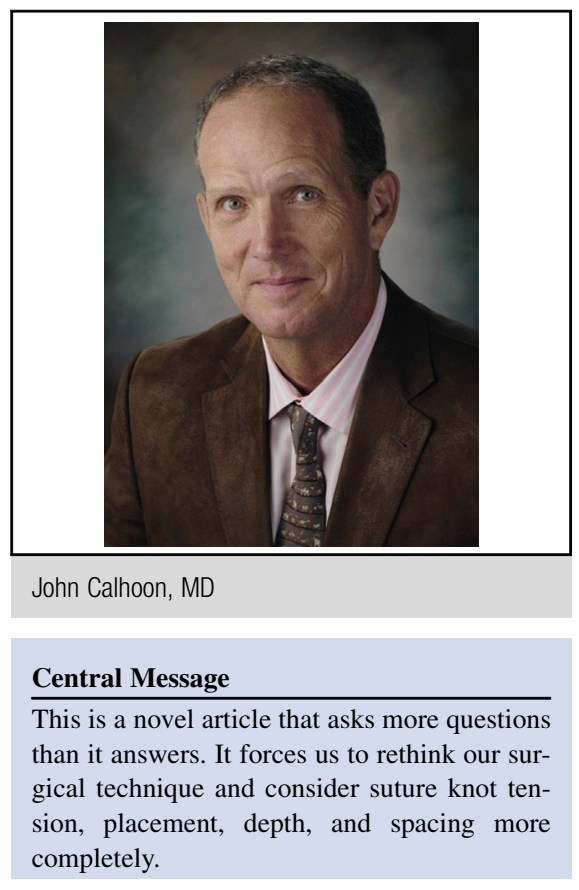

See Article page 131

aortic arch tissue. Anecdotally, these patients illustrate subtle technique differences that manifest as suture line

In the end, surgeons are judged by their outcomes. This investigative tool could improve surgical training techniques and should be married with the other surgical judgment necessary to perfect technique; suture spacing, sizing, and depth; and annular and ring placement. I loved the article, because it made me think more deeply about how and what we do daily. Let's hope more work such as this will follow and allow us all to perfect our technical skills in simulated environments before the game is on

1. Pierce EL, Bloodworth CH IV, Siefert AW, Easley TF, Takayama T, Kawamura T, et al. Mitral annuloplasty ring suture forces: impact of surgeon, ring, and use conditions. J Thorac Cardiovasc Surg. 2018;155:131-9.e3. 